\title{
A “Imperial" mcdonaldização: cruzamentos glocais num antigo café portuense
}

Antônio Augusto Oliveira Gonçalves ${ }^{1}$

\section{Resumo}

O espaço que hoje alberga o McDonald's Imperial na cidade do Porto foi antes um suntuoso café na Avenida dos Aliados. Fundado em 1936, o Café Imperial foi construído no lugar do extinto Café Central. O presente artigo propõese ao exame do status quo do Imperial tendo por horizonte as implicações mútuas e os cruzamentos sincréticos do local com o global e vice-versa. As ilações auferidas da pesquisa indicam o enleamento de práticas culturais distintas e a regionalização das interações sociais. No que se refere ao espaço, o processo de estandardização e descaracterização formal encetado pelo McDonald's de 1990 até novembro de 1995 promoveu a emergência de um padrão arquitetônico de massificação do erudito. Além disso, a conjugação de cenários, personagens sociais e comportamentos que daí emerge cria um panorama de glocalização da realidade. Dessa maneira, descortina-se um duplo processo de ressignificação do espaço, as pessoas fazendo uso dos recursos materiais disponíveis - ambiência, lugares, mesas vagas, seleção de itens para alimentar-se, sanduíches, sopas, sorvetes, cafés, cervejas - reapropriamse do ambiente. Por outro lado, o McDonald's é cônscio de seus públicos consumidores, logo insere alguns produtos próprios da cultura portuguesa, propiciando condições para o primeiro processo.

\section{Palavras-chave}

Café Histórico. McDonald's. Sincretismo. Interação Social.

1. Graduando do curso de Ciências Sociais da Universidade Federal de Uberlândia e do curso de Psicologia da Faculdade Pitágoras de Uberlândia. E-mails: antonio@soc.ufu.br; antonioaugusto.sociais@hotmail.com. 


\title{
The "Imperial" mcdonaldization: glocal crossings in an ancient coffee shop in Porto
}

Antônio Augusto Oliveira Gonçalves*

\begin{abstract}
The place that now houses the Imperial McDonald's in the city of Porto was in the past a sumptuous coffee shop on the Avenida dos Aliados. Founded in 1936, Café Imperial (Imperial Café) was built where existed before another coffee shop, Café Central. This article aims to analyze the status quo of Café Imperial, having as horizons the mutual implications and syncretic crossings of the local with the global and vice versa. The conclusions reached from this research indicate the tangling of distinct cultural practices and regionalization of social interactions. Regarding the space, the standardization and formal mischaracterization process done by McDonald's, from 1990 to November 1995, emerged an architectural pattern of erudite massification. Moreover, the combination of scenarios, characters and social behaviors emerged from this situation creates a panorama of reality glocalization. In this way, it unfolds a double process of space resignification; when making use of the material resources that are available - ambience, places, unoccupied tables, food choices, sandwiches, soups, ice cream, coffees, beers -, people reappropriate the environment. Furthermore, McDonald's is aware of its consumer public, therefore it offers some Portuguese culture products, creating the basic conditions so the first process can happen.
\end{abstract}

\section{Keywords}

Historic Coffee Shop. McDonald's. Syncretism. Social Interaction.

\footnotetext{
* Undergraduate student in Social Sciences at the Federal University of Uberlândia and in Psychology at the Pitágoras College in Uberlândia. E-mails: antonio@soc.ufu.br ; antonioaugusto.sociais@hotmail.com.
} 


\section{Introdução}

\section{A chegada}

Eram 18 horas. O manto de luz lábil de primavera dava lugar a almofadas negras que cobriram de penumbra as ruas íngremes confluentes à principal artéria urbana do Porto, a Avenida dos Aliados. A cinzenta nebulosidade não é uma exceção climática nessa cidade atlântica, mas algo corriqueiro na aura sisuda e austera do Porto, como bem frisa a docente de estudos literários Maria de Lourdes Belchior Pontes (1999) ao rememorar o casamento meio escondido pela névoa de D. João I com D. Filipa na Sé. Numa rua transversal, em frente à esplanada de um café, uma dupla de músicos interpretava uma canção brasileira, contudo o ritmo melódico parece ter uma gênese no fado português. Defronte, uma senhora vetusta dança de maneira desengonçada e pouco primorosa nos movimentos, resvalando numa espécie de ataxia festiva. Ao redor, turistas e transeuntes assistiam à cena numa mescla de curiosidade ingênua com algum tom de sátira e ironia. Aquilo prendeu minha atenção por alguns instantes, escutei comentários jocosos em português, destacando-se a pronúncia portuense em que o "v" dá lugar ao "b". Glosas como "olha a belha a dançar!" ou ainda "bê, bê, toda fresca!". Essa fonética talvez se deva à proximidade geográfica com a Galícia, em Espanha, um sotaque veementemente vincado. Soma-se ao ar frio e denso uma tênue precipitação que, aos poucos, rouba os sorrisos e gargalhadas e, à medida que as gotas se tornam espessas, as pessoas escorrem pela Avenida em busca de abrigo. A senhora que dançava não se demoveu. Já tinha encontrado o seu refúgio - a música.

Num ato de aquiescência, deixei-me conduzir pelo instinto fugaz das pessoas que, tal como eu, fugiam da mistura de nevoeiro e orvalho daquele anoitecer de sábado. Foi quando reparei que aquele magote levava-me para onde me dirigia antes de parar e contemplar a senhora inebriada pelo som latino. O abrigadouro escolhido pela maioria das pessoas foi o salão de um antigo café portuense e atual unidade da cadeia de fast-food McDonald's, mais conhecida pelo nome do estabelecimento que a antecedeu, o Café Imperial. Para mim, mais do que um abrigo imediato nesse dia de chuva, era o alvo donde iria realizar a minha observação etnográfica exploratória. Antes de pisar no umbral, num passo apressado, vislumbrei, por debaixo das mãos que cobriam o meu rosto da chuva, aquela enorme e majestosa águia de asas abertas que já tinha visto reluzente em dias de sol. Nesse momento, no entanto, afigurou-se menos brilhante. Entrei. As observações que recolhi ao longo de quatro dias consecutivos não podem ser interpretadas à margem do contexto sócio geográfico.

Pensemos num dispositivo fotográfico. Sua constituição permite ao fotógrafo desde a focalização de detalhes até ao registro de fotogramas dantescos - entre uma escala e outra existe uma série de gradações medianas. Assim, o fotógrafo desliza da teleobjetiva à grandeocular, possibilitando ir desde dimensões macro a microscópicas. O enfoque teleobjetivo das percepções permite assegurar na imagem da memória algumas regularidades hipotéticas. Corresponde àqueles fotogramas de satélites de uma cidade, em que neles constatamos certas unidades homogêneas, bairros residenciais em determinadas zonas, um aglomerado verde, pressupondo que seja um parque urbano, além das cornubações de prédios na região central. Entretanto, se adentrarmos nas zonas residenciais, averiguamos que existe uma grande heterogeneidade de prédios, praças com árvores e todos aqueles elementos que, vistos na teleobjetiva anterior, agora se apresentam profundamente híbridos, circunscritos num contexto. A contextualização 
converter-se-á numa ferramenta seminal para a ilustração das percepções gerais da observação etnográfica, porém tais recursos são abstrações razoáveis, falta elucidá-las ao nível empírico.

Apesar do objeto de análise não ser propriamente o espaço urbano, não podemos isolar e tornar inócuo o restaurante McDonald's das influências externas. Assim, é premente ter em conta a rede de transportes que o serve, os cafés envolventes, as empresas hoteleiras, os bancos, os monumentos turísticos e o restante de serviços oferecidos nas áreas circundantes. A antropóloga brasileira Carmem Rial (1997), no seu estudo das cadeias de fast-food em Paris, averigua que esses restaurantes não são instalados aleatoriamente. Existe uma intencionalidade e estratégias sutis de marketing que podem passar despercebidas aos mais incautos. Claramente, de um ponto de vista econômico, será mais viável implantar um negócio na confluência de condições propícias à sua prosperidade, uma observação feita in loco pela autora, que estabelece interseção entre a localização dos fast-foods e os fluxos turísticos. A inserção estratégica no tecido urbano consiste no posicionamento em linha com os principais monumentos, apontando para a população de visitantes que transitam pela cidade. No caso do McDonald's Imperial, a mesma lógica é aplicada, afinal esta unidade situa-se na Avenida dos Aliados, que, por si só, já se configura numa atração turística, com o edifício da Câmara Municipal num extremo e o Hotel Intercontinental em outro. Ademais, o restaurante está próximo da ex libris da cidade do Porto, vulgo Torre dos Clérigos, e ainda da Ribeira, da Reitoria da Universidade do Porto e do centro histórico da Sé. Além disso, este restaurante é servido por três estações de metrô do Porto que fazem a ligação desde o Aeroporto Francisco Sá Carneiro à baixa portuense, a saber: estação da Trindade, Aliados e São Bento. Nota-se que essas três estações estão fisicamente separadas por poucos metros de distância. O que, à vista desarmada, poderia ser um esbanjamento de recursos financeiros, se revela uma tática necessária na medida em que favorece a mobilidade dos utentes numa zona central como é a dos Aliados.

Existem também as linhas ferroviárias da estação de comboios de São Bento, que se apresenta como uma estação de início e fim de viagem, pois, na malha ferroviária, São Bento é necessariamente o ponto de chegada e de partidas à baixa do Porto. Esta última está ligada à estação de Campanhã, que é o centro de confluência de comboios provenientes de todo o país e da Espanha, na zona norte. Acrescido às linhas de metrô e comboio, coexiste ainda uma densa oferta de ônibus com paragens por toda a Avenida dos Aliados e nas regiões limítrofes. No centro histórico, área vizinha aos Aliados, a oferta de transporte perpassa também pelos carros elétricos remodelados e recuperados e o funicular dos Guindais, cuja linha foi reaberta em 2004 após um desastre grave, ocorrido em 1893, que ditou o seu encerramento dois anos depois da primeira inauguração. Por fim, o sistema de transportes na baixa do Porto é complementado pelos autocarros e comboios turísticos, sem função explícita de mobilidade para os autóctones.

\section{O Café Imperial}

Conforme Mendes (2012), o espaço que hoje alberga o McDonald's Imperial foi antes um suntuoso café na Avenida dos Aliados. Fundado em 1936, o Café Imperial foi construído no sítio do antigo prédio do extinto Café Central. Na fachada do prédio, encontra-se uma imponente águia de bronze, de Henrique Moreira. O projeto dos arquitetos Ernesto Korrodi e Ernesto Camilo é constituído por dois pisos: um que dá acesso à Avenida dos Aliados - salão principal de entrada - e outro que está localizado num piso subterrâneo que fora, outrora, um salão de bilhar. No salão da entrada, ao fundo, vitrais 
em art déco, de autoria de Ricardo Leone. Os vitrais fazem alusão a dois processos relativos ao café: à esquerda, um refinado casal a proceder à conduta ritualizada do consumo de café e, ao lado direito, representações do ciclo cafeeiro no Brasil - seu cultivo, transporte por navio até a descarga e, finalmente, o café servido a mesa. As paredes laterais são ornadas com frisos de baixo relevo de Henrique Moreira, representando motivos de dança. Abaixo dos painéis de estuque, extensos espelhos de cristal que, ao centro, ostentam candeeiros com adornos transparentes. Na arquitetura do teto, saltam aos olhos quatro faustosos lustres, conferindo uma aura de distinção e requinte ao espaço. Em decorrência da remodelação e reconversão do Café Imperial, ocorridas na primeira metade da década de 1990, parte dos elementos decorativos foram eliminados, outros adquiriram novos componentes e alguns foram completamente adaptados às tendências estéticas e design característico da cadeia de restaurantes McDonald's. Nesse sentido, coloca-se em relevo um processo de hibridizações dentro do espaço. Os exemplos cabais dessa bricolagem são: a inserção do lettering característico da cadeia de fast-food junto à "Águia Imperial" de bronze, fornecendo o nome da franquia, McDonald's Imperial. Além disso, na inauguração do café, seguindo certos preceitos da Exposição Colonial Portuguesa de 1934, a águia de bronze tutelava uma porta giratória, que foi retirada durante a remodelação. Em tempos de contestação contra a ditadura salazarista em Portugal, os manifestantes adentravam pelo salão do Café Imperial e eram protegidos pela porta giratória que barrava a entrada da polícia. A fachada do café foi guarnecida com dois luminosos em " $M$ " em cada lado da antiga porta giratória. Os frisos em baixo-relevo de Moreira, que outrora eram revestidos em tons prateados, encontram-se atualmente recobertos de dourado, talvez por uma menção simbólica aos Golden Arches do " $M$ " daquela cadeia de fast-food internacional. Os vitrais de Leone, que antes ocupavam quase toda ambiência da parede dos fundos, hoje são sobrepostos na parte inferior pelo balcão e os painéis da ementa do restaurante (COSTA, 2004; MENDES, 2012). As mesas baixas com três ou quatro cadeiras foram, em parte, substituídas por poltronas assimétricas, sofás retangulares e mobiliário alto e alongado, porém ainda resistem algumas das antigas mesas nos dois pavimentos, medrando certa inclinação de cruzamentos tradicionais e vanguardistas ao espaço. A sala de bilhar no piso inferior foi totalmente adaptada ao modelo do McDonald's, caracterizada com linhas harmoniosas e materiais de madeira e couro. Mendes (2012) identifica o antigo Café Imperial segundo três critérios de capitulação e valorização do apanágio de um café histórico: o valor de memória, o Imperial colmata esse critério por ser um dos dois únicos espécimes na Avenida dos Aliados, na década de 30 do século $X X$ até meados da centúria, que estimulou a vida cultural e a animação no seio urbano da cidade; o valor artístico, faculdade inexorável ao café, devido ao requinte da combinação entre os vitrais de Leone com os painéis de baixo-relevo e a ostensiva "Águia Imperial" de Moreira; e, nos meandros dessa ilação, Mendes aponta o critério de valor para a história, tendo em conta que o café foi frequentado por personalidades insignes da sociedade portuense do século XX do círculo das artes, música e letras - dentre eles o professor de português, literatura e linguística Óscar Lopes, a violoncelista Irene Freitas, o folclorista Armando Leça e expoentes como, por exemplo, João Gaspar Simões.

Os critérios classificatórios de Mendes remetem ao modelo tricotômico de cultura. ${ }^{2}$ Apesar de o Café Imperial surgir numa época

2. Consoante às trilhas do pensamento de Lopes (2008), o modelo tricotômico de cultura se entabula já no Antigo Regime com o advento das instâncias de consagração, os mecenas e as academias, agências responsáveis pela 
em que os ditames da cultura de massas começavam a tomar corpo em pleno cenário do capitalismo fordista dos gloriosos anos trinta, parece haver alguma filiação mais ou menos explícita com a cultura erudita, ou melhor, a alta cultura. De acordo com a exegese crítica do sociólogo português João Teixeira Lopes sobre a teoria geral do campo artístico de Bourdieu (2008), as regras gerais de funcionamento da cultura erudita pressupõem certos elementos diferenciadores propalados na característica única e singular na "aura" da obra, públicos muito restritos e a agência de consagração hegemônica efetivada pelos pares e as academias. As próprias academias são, por excelência, a "Torre de Marfim", que, além de conservarem os valores oriundos do campo, definem os seus limites, levando a maior resistência às exigências mundanas, às heresias dos lucros materiais, resguardando, então, o grau de autonomia da produção artística (BOURDIEU, 1997; LOPES, 2008). Assim, os pares dispõem de conhecimento de causa, com armas, métodos, técnicas e instrumentos científicos, uma barreira que protege a cidade artística - ou científica - das ações deslocadas e impróprias de fundamentos de consecução e avaliação externos. Nas circunstâncias do Café Imperial, o valor artístico corresponde às três principais obras: a águia de bronze, os painéis de estuque e os vitrais. Logo, a arte rege-se por regras próprias, não acontece na lógica sem lógica do milagre social. Há um sistema que organiza as crenças, valores das artes, as posições dentro do campo e a forma como as pessoas se relacionam com as artes. Isto é, as posições existem apenas umas em relação às outras. A descrição de Mário Cláudio sobre a obra de Leone consegue deslindar melhor os princípios autônomos e relacionais no campo artístico (2000, p. 18):

E, maravilhoso como nada que se lhe comparasse, assombrava-me o gigantesco painel de vidro martelado do Imperial, figurando um par ilustre, de tão esguio, agudo de ombros e de gestos, a paulatinamente saborear o seu café, inserido num quadro de delicioso tropicalismo, enquanto rebentavam os desgraçados dos indígenas, no carreto de sacos e sacos do precioso pó de beberragem [...].

A expressão "como nada se the comparasse" traduz a natureza irrepetível e ímpar dos vitrais, o eflúvio que fornece um sentido único para um ator único, a perspectiva da "arte pela arte, da arte como finalidade sem fim" (LOPES, 2008, p. 24). O capital específico recai em certa autoridade carismática de Leone, o criador do "gigantesco painel de vidro martelado" que, por meio de um artifício mágico, consegue impor as suas idiossincrasias e apreciações como universais e legítimas. A posição da águia de Moreira, por sua vez, segue os gostos e costumes socialmente reconhecidos pela Exposição Colonial Portuguesa. Tal evento, ocorrido dois anos antes da inauguração do Imperial, se apresenta como uma agência de consagração em que os pares

criação cultural que paulatinamente se diferenciam. Elias (2000), ao analisar o processo civilizacional na Europa, sublinha a distância aristocrática, a formulação de hábitos distintos e distintivos para assegurar a consolidação da grande tradição vis-à-vis à pequena tradição, que se vincula a face marginal e residual dos costumes, abafada na nostalgia da pré-modernidade. Do modelo bipolar, avultam-se os usos a-históricos das concepções de cultura, mormente, civilizado/bárbaro, grande/pequeno e, assim, a mesma pulsão essencialista do alto/baixo é catalisada pelas ideias iluministas com o desenvolvimento da ciência moderna, de uma razão universal que vem substituir a religião. A tricotomia é alcançada com o avanço da revolução industrial na fase fordista, na qual a cultura de massas transmuta-se num mito do denominador comum de gostos e perspectivas, donde cariz homogeneizante faz-se sentir. O ser oriundo dessa conjuntura cultural não é nem erudito e muito menos detentor de costumes folclóricos, mas sim um tipo médio universal, que Herbert Marcuse denomina de "homem unidimensional" (LOPES, 2008; ELIAS, 2000; NAZÁRIO, 1998). 
são, concomitantemente, o corpo de jurados e a parte interessada (BOURDIEU, 1994), isto é, um campo artístico que diferencia os dominantes dos dominados, cuja dominação dos dominantes provém do monopólio da doxa. Coaduna-se ainda, no esquema de Lopes, a noção de públicos muito restritos que se imbrica ao valor para a história de Mendes (2012), dos frequentadores assíduos do café, figuras distintas do Porto na época, tais como João Gaspar Simões e Óscar Lopes.

Por outro lado, o processo de estandardização e descaracterização formal

Imagem 1 - Frontispício do McDonald's Imperial.

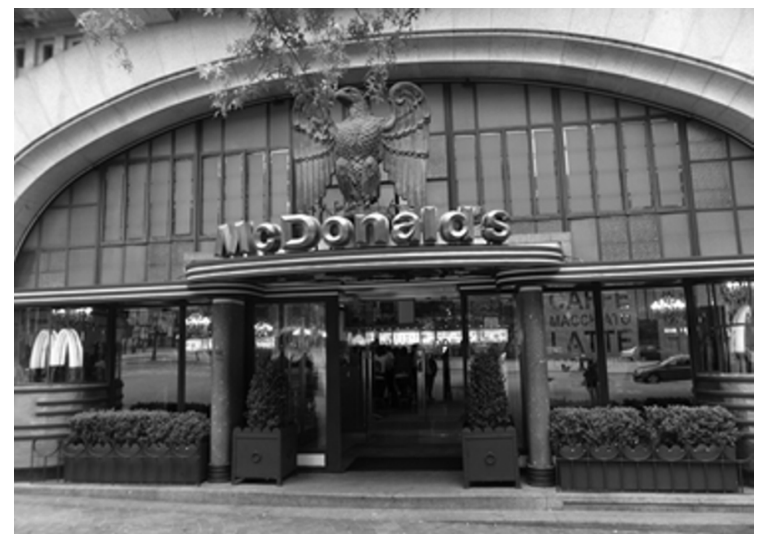

Fonte: Acervo do autor. encetado pelo McDonald's de 1990 até novembro de 1995 promoveu a emergência de um padrão arquitetônico e espacial de massificação do erudito. Esse oximoro pode ser atestado na remodelação do cenário físico em geral, na retirada de parte das mesas e do bar com teto de cristal, popularmente conhecido como sacristia. Quiçá os sinais mais significativos sejam o revestimento dourado dos painéis em baixo-relevo e o arranjo do balcão e do painel iluminado da ementa sobrepondo os vitrais, conforme se visualiza nas imagens abaixo:

Imagem 2 - Ao fundo, os vitrais em art déco.

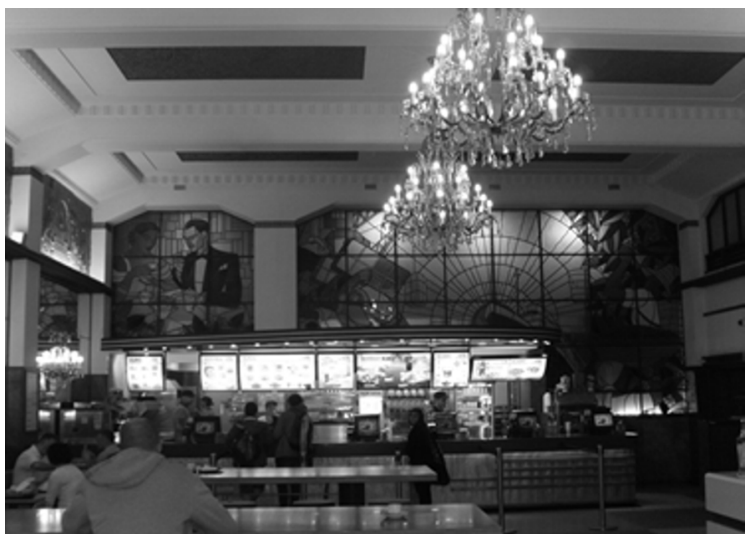

Fonte: Acervo do autor.

Imagem 3 - Acima dos espelhos, os painéis de estuque.

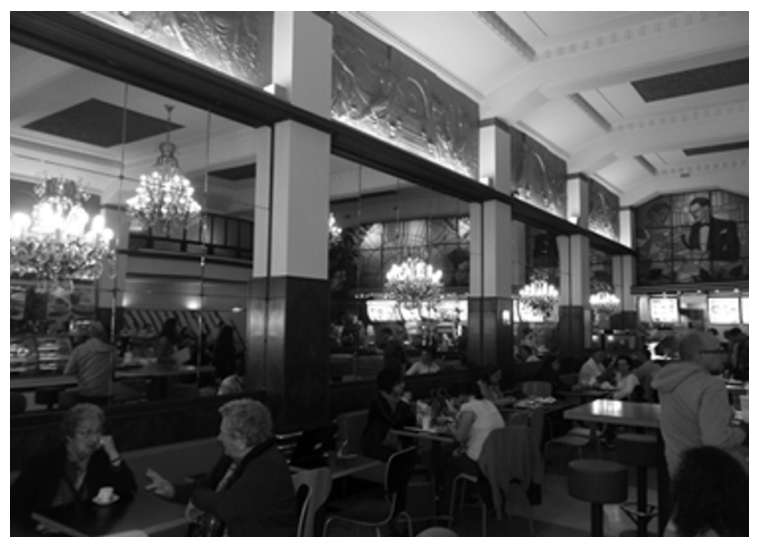

Fonte: Acervo do autor. 
Descortina-se, portanto, uma composição que complexifica e gera algumas incongruências no modelo hierárquico de níveis de cultura ${ }^{3}$. Na fase atual do capitalismo, o que Lash e Urry (1987 apud LOPES, 2008) intitulam por capitalismo desorganizado, as recomposições crescentes do modo de produção geram efeitos nas relações entre a economia e a cultura. A expansão do capital implica a dilatação da economia para setores ainda hesitantes à mercantilização. As práticas culturais, por sua vez, não se fundamentam num vacúo de desinteresse, como se fossem estranhas a essa lógica, pelo contrário, sofrem o impacto econômico ao mesmo tempo em que a economia se culturaliza. Mesmo que infinitesimal, o mercado processa a diferença e a singularidade cultural no âmago das mercadorias, desmassificando-as relativamente. Exemplar a respeito disso é a introdução de refeições tipicamente portuguesas no cardápio do McDonald's em Portugal, a saber: a McBifana ${ }^{4}$ dentre os sanduíches e, nos acampanhamentos, duas opções diárias de sopa, além dos pastéis de nata no McCafé.

Nessa perspectiva, golpeando a tricotomia cristalizada e inerte entre a cultura erudita, a cultura de massas e a cultura popular, Lopes (2008) enseja uma nova formulação teórica menos determinista e mais polifônica. Isso não quer dizer que o autor português faça do sincretismo uma doutrina, mas antes procura por sínteses hodiernas, rascunhos explicativos sempre provisórios, incertos e não acutilantes.
Com isso, o sociólogo lusitano propõe uma complexa análise combinatória da produção de cultura que é fecunda na interpretação do status quo do Imperial. Haja vista que as impurezas e o recrudescimento das contaminações culturais são inclinações acentuadas num cenário que enleia a ortodoxia do erudito com o cariz homogeneizador da cultura de massas e congrega, ainda, a invenção-resgaste da tradição contida na ementa do McDonald's, engendrando, assim, a herança popular no panorama de massificação da alta cultura do Imperial. A reviravolta de costumes incutida pelo fast-food corrobora, por vezes, numa sensação de vertigem, de deambulações na decodificação da trama do "sistema" (RIAL, 1997). O próprio sistema faz solicitações que se chocam com os valores de uma educação civilizada. Colocam-se em xeque as regras da boa conduta à mesa ao comer com a mão? Tal ato é sinônimo de incivilidade? Altera por si só o desenho do limiar de reatividade aversiva no processo civilizacional de Elias (2000)?

\section{Um espião em campo}

Segundo Geertz (1978), o trabalho etnográfico consiste em registrar, anotar o "discurso social" e torná-lo passível de pesquisa. Nessa ação, o cientista social transforma o fato numa inscrição, um relato que pode ser averiguado quantas vezes for necessário.

3. Para Lopes (2008), a comodidade analítica em que repousam os três níveis de culturas corresponde à configuração social resultante da dupla revolução, francesa e industrial, favorecendo, assim, o advento de sociedades tripartidas, divididas entre a burguesia, a pequena burguesia e o proletariado. Por consequência, emergem três perspectivas de mundo, nomeadamente, a cultura erudita, a cultura de massas e a cultura popular, com distintos elementos diferenciadores, públicos, capitais específicos e respectivas agências de consagração hegemônica. A tricotomia assimétrica assente numa dimensão estanque e hierarquizada entre os três universos culturais. Nela, não há lugar para o sincretismo somente para os essencialismos que pululam cada esfera cultural (LOPES, 2000; 2008).

4. A McBifana é uma ressignificação a la McDonald's de um tradicional sanduíche português feito de bife suíno, ou como dizem os portugueses "fêveras de porco", preparado com vinho, alho e servido com o pão aquecido. Na versão do McDonald's, ainda constam duas opções, com ou sem molho de mostarda, contudo há também outras variações, como a McBifana à Chefe, com queijo cheddar, e a McBifana à Cervejeira, com molho de cerveja. 
Na fala, a tarefa da escrita fixa é transcrever o que foi "dito", não o ato de falar, mas o significado do ato de falar. Trata-se de uma interpretação. Por isso, os relatos ou ensaios antropológicos são interpretações de segunda ou terceira instâncias, a de primeira será sempre do "nativo", pois ele também faz uma interpretação de sua própria cultura. A descrição densa apresenta alguns aspetos essenciais: é hermeneuta - interpreta o fluxo do discurso social e busca resgatar o "dito", a fim de fixálo em modos pesquisáveis - e é microscópica.

Nessesentido, Lopes (1997), no preâmbulo epistemológico de sua dissertação, condensa rotinas metodológicas e teóricas de grande valia sobre a observação direta, o que o sociólogo português designa por "versão suave do trabalho de campo". A natureza de interferência mínima da observação direta implica certos códigos de impessoalidade e anonimato. Não é por acaso que, com efeito, o pesquisador se compare à figura do espião em campo, recaindo num véu de invisibilidade. Porém, tal prerrogativa não quer dizer que o pesquisador deve tãosomente observar o observável, pelo contrário, devido ao caráter da imprevisibilidade ${ }^{5}$ "em cena", da pluralidade de situações e problemas que daí pode medrar, o método conduz a procedimentos bastante diversificados, desde o registro de indumentárias, das posturas, dos gestos e meneios até dos símbolos evocados. Ao contrário da observação participante, a modalidade direta não acarreta a subjacente integração do pesquisador nas comunidades em estudo, evitando, assim, a modificação do tecido social. Desse modo, o anonimato permite perceber o despontar de comportamentos que, numa apreciação superficial, poderiam aparentar-se irrisórios, além de minutar os diálogos no seu quadro de "espontaneidade".

Em virtude da morfologia do espaço no
McDonald's, seria redutor colher observações apenas num dos pisos. Dessarte, procuramos dedicar o mesmo tempo de análise em ambos os pavimentos. Os dados em seguida apresentados, são o reflexo de quatro dias consecutivos de observação, dos quais dois dias de um fim-de-semana. Para além disso, com intuito de comparar a diferença dos públicos, do consumo e das maneiras de estar à mesa, realizamos as observações alternando-as entre as horas de almoço e jantar e deambulando, rotativamente, entre os diferentes ambientes, de modo a dar uma visão global e holística.

\section{O jogo de espelhos}

A existência de espelhos de cristais nas duas paredes laterais do salão de entrada do antigo Café Imperial relaciona-se, sobremaneira, com encenação, a apresentação do "eu", do self. O autorreflexo dos espelhos entre si não gera apenas um efeito puramente físico, tem um rescaldo no âmago da organização espacial da interação. Qualquer pessoa que entre no McDonald's passa por eles. Os espelhos fomentam o comportamento regulado no piso superior, por possibilitar que um indivíduo vejase através de seus reflexos e consiga, ainda, ver as pessoas ao seu entorno, os olhares, gestos, movimentos, interpretando-os. Para Goffman (1993), o espaço interfere na vida social enquanto condicionante físico das interações. Ainda no caso do McDonald's, arrisco-me a ir um pouco mais além. No acesso aos telefones móveis e portáteis, mesmo que a franquia disponibilize gratuitamente o sinal de Wi-Fi dentro de suas dependências, os espelhos exercem uma espécie de ação de constrangimento social e autorregulação nos indivíduos, na medida em que o conteúdo que eles acessam pode ser refletido nos espelhos e ser visto pelos que

5. Nesse ponto, recordo-me ainda, sem a frieza das anotações de campo e com alguma dose quente da boa lembrança, de uma situação que inesperadamente chamou minha atenção: dois managers do Imperial expulsando a bofetadas e gritos uma pedinte. 
ali estão, acicatando, assim, a emergência de comportamentos menos descontraídos, tanto na presença física quanto no conteúdo dos sites visitados. Acrescido a isso, a conduta codificada dos agentes tem origem na modelação estética da entrada: com vitrines e porta de vidro transparente, facilitando que os transeuntes na Avenida dos Aliados vejam quem está dentro. Reciprocamente, os clientes do McDonald's vêem toda a movimentação exterior. Ao fazer a releitura de minhas anotações de campo, encontrei o seguinte comentário "Tá a chover!". O que parece uma construção frásica exclamativa carrega em si argumentos mais do que suficientes para sustentar a alegação da influência exterior-interior, vice-versa, pois o ato de ver (mais do que o de escutar ${ }^{6}$ ) a chuva no âmbito exógeno tem reverberações no comportamento porta adentro.

Logo, ainda pelo escopo analítico de Goffman (1993), partindo dos preceitos que o espaço não é homogêneo e sim regionalizado, pude perceber o que existia de internamente regionalizado naquele cenário por meio da distinção categórica assinalada. O excerto abaixo sintetiza os conceitos de região de fachada e região de bastidores:

Existirá assim uma região de bastidores contendo utensílios que dão forma ao corpo, e uma região de fachada dispondo de certos apoios fixos. Existirá uma equipa de pessoas cuja actividade encenada, articulando-se nos suportes disponíveis, constituirá a cena a partir do qual emergirá o eu da personagem desempenhada, e uma outra equipa, audiência, cuja actividade de interpretação se revela necessária a essa emergência. $\mathrm{O}$ eu é um produto de todas estas combinações, e todas as suas partes exibirão as marcas dessa origem. (GOFFMAN, 1993, p. 295).

A percepção que os pisos superior e inferior, respectivamente, poderiam ser interpretados enquanto "fachada" e "bastidores" pareceu a mim uma saída teórica razoável, uma vez que os tipos sociais observados no salão principal exprimiam alguma prospectiva de encenação. Por exemplo, jovens visualizavam seus reflexos nos espelhos, idosos eram contidos nos movimentos, famílias inteiras nas mesas mantendo pouco ou quase nenhum diálogo. No pavimento inferior, por seu turno, os códigos de controle e gesticulação contida perdiam a sua vez e o comportamento informal tornava-se uma constante no quadro. Casais sentados, em demasiada proximidade entre si, trocando carícias; as famílias, antes monótonas, agora desengonçadas (uma filha dá um sopapo na cabeça da mãe). No decurso dos dias de observação, fui angariando novas pistas de forte propensão à teatralidade inscrita em Goffman. Assim, entre um piso e outro, foi-se delineando uma fina distinção nos tipos sociais: no salão de entrada, predominam idosos, turistas, imigrantes, pedintes, famílias, pessoas sozinhas, indivíduos com malas, turistas que apenas fotografam o salão e, em menor proporção, grupos de jovens, casais e adolescentes; enquanto que, no inferior, transparece um microcosmo, convívio de jovens, casais, grupos de amigos, adolescentes, famílias e leitores sozinhos e, em minoria, idosos (em grupo ou sozinhos), turistas e pedintes. Foi quando me deparei com a seguinte situação numa manhã frenética de segunda-feira, no pavimento inferior:

\begin{abstract}
A minha primeira imagem no campo foi de uma fila de jovens sentados num conjunto de sofás e cadeiras, entremeados de mesas para duas pessoas, mesmo com relativa distância entre as mesas, eles esforçavam-se para se comunicar por meio da gesticulação. Num átimo, um grupo de vinte ou mais crianças ocupa a praça (centro) do pavimento, provenientes da freguesia de São Julião do Tojal (notava-se pela camiseta dos três instrutores que os acompanhavam). A quantidade de indivíduos num mesmo recinto logo produziu efeitos na chegada
\end{abstract}

6. Devido à música de fundo, focava-se mais no que era observável do que audível. 
dos novos, pessoas desciam as escadarias procurando por um lugar disponível. Havia, entretanto, lugares vagos, majoritariamente em mesas com três cadeiras que cercavam o entorno e mesmo que apenas uma ou duas pessoas as ocupassem, restando assim um ou dois lugares disponíveis, os clientes não se sentavam e subiam ao piso da entrada buscando mesas desocupadas. Em instantes, formou-se um aglomerado de pessoas em pé nos corredores entre a praça e as mesas para grupos, pois estavam à procura ou a aguardar um lugar para se sentar. Os que estavam em pé, por meio de gestos e expressões faciais, davam a entender a sua espera pela mesa, apesar de a prática distintiva de não se sentar com estranhos em mesas para três ou quatro pessoas. Isto se demonstra, empiricamente, pela jovem sentada sozinha numa mesa circular que, após tomar o seu café, abre livros e apontamentos e começa a ler, porém, devido a um grupo de adolescentes que se posiciona ao lado de sua mesa, ela se vê impelida a deixar o lugar.

Pela dinâmica do piso superior, vê-se que os idosos e pedintes poucas vezes descem ao antigo salão de bilhar, espaço esse geralmente composto por jovens, famílias, casais e os "mcleitores"7. Em contraposição, os últimos no contexto descrito acima, mesmo com assentos disponíveis no salão de entrada, preferem um lugar imediatamente após o descer das escadarias. Essa distribuição heterogênea, e, portanto, localizada, dos atores no cenário, devese somente a atmosfera frontal ou de retaguarda dos ambientes considerados? Tal qual uma força paradoxalmente centrípeta-centrífuga que atrai determinados agentes e afugenta outros?

A alegação não é de todo verdade, afinal, com o transcurso da observação etnográfica, foi ficando cada vez mais nítido que, mesmo na região de fachada, no piso superior, emergem comportamentos típicos de bastidores, em cotejamento com o inferior, em menor incidência, ainda com a roupagem predominante da frente. Determinadas pessoas emitem risadas altas, gestos desengonçados, indivíduos que dormem sentados nos sofás. $\mathrm{Na}$ região de fundo, por sua vez, parecem existir comportamentos regulados, casais que comem silenciosamente, com algumas restrições formais, adolescentes que se posicionam na praça do pavimento para serem vistos. Todos esses elementos configurados, sincreticamente, numa trama característica de retaguarda. Há um aporte dialético entre as regiões de fachada e bastidores. Existem bastidores na fachada e fachada nos bastidores (LOPES, 1997).

\section{Usos e apropriações do espaço: do consulado alimentar ao lugar de anonimato}

Para Rial (1997), a fórmula de sucesso do fast-food advém, em larga medida, de uma matriz de repetição do que nele contém. A repetição,

7. É comum a presença de indivíduos solitários, em número reduzido, mas diferem das atividades normalmente efetivadas pelas pessoas sozinhas do piso superior (acessar a internet no telefone móvel, nos tablets, comer algo enquanto observam os agentes que entram no recinto). Esses indivíduos leem um livro, anotações de um caderno, desfocam pouco a atenção com os clientes que entram e saem do pavimento, porém a presença social daqueles agentes estranhos parece ser importante para eles. Trata-se de um desdobramento lógico. O Porto é uma cidade com espaços públicos para leitura. Nomeadamente, na região central onde se situa o McDonald's, existem, pelo menos, dois sítios, a Biblioteca Pública Municipal do Porto e a Biblioteca Almeida Garrett, além dos cafés e centros comerciais. Poderíamos inferir, pela questão dos horários e dias de funcionamento das bibliotecas, afigurar-se enquanto um fator potencializante dessa presença, todavia o argumento é mais ou menos inconsistente porque, na observação, constatamos que os leitores estão no McDonald's em tempos diversos e espaçados - no período da tarde 13h, 15h e 18h, horários em que as bibliotecas estão abertas -, além do funcionamento de segunda à sábado. Então, quase num sentido weberiano, questionamos qual a motivação dessa ação social? Eles querem ver e ser vistos? A ambiência geral, a música, a luminosidade e as pessoas agradam-lhes? 
à primeira vista, poderia ser compreendida com um pendor de monotonia, porém tranquiliza os turistas, confundidos pelo desconhecido, o inédito. A serialidade, nos termos de Umberto Eco (apud RIAL, 1997), reproduz certa sensação do familiar, na segurança de estar no conhecido, aquilo que Bachelard designaria por um lugar de repouso. Mesmo que nas suas cidades de origem os turistas não frequentem as redes fast-foodianas, quando chegam numa cidade turística, provavelmente, vão apropriar-se das unidades do McDonald's, Burger King, KFC, tal como um consulado alimentar, um âmbito de sabores "quase nacional" dentro de um território estrangeiro. São pontos de referência no meio do desconhecido, permitem resguardar o paladar das obscuras aventuras na cozinha local, exótica. Não é por acaso que os turistas vão aos fast-foods consultar um mapa, descansar depois de uma viagem demorada, fazer telefonemas.

No cerne das figurações psicológicas, esses restaurantes "criam uma territorialidade fixa que compensa as incertezas das derivas" (RIAL, 1997, p. 15). No caso do Imperial, incorpora-se, ainda a esse pressuposto, a beleza arquitetônica que serve de atrativo e chamariz aos novos nômades. Giddens (1997) interpretaria que a continuidade inscrita nesses restaurantes cria um preâmbulo de certeza, de antevisão do risco, numa tentativa de colonizar o futuro para si próprio, precavendo as descontinuidades, as possíveis estranhezas e impotências geradas pela barreira linguística, diferença de horários, de clima etc. Aliás, a própria escolha de pratos nas ementas das cozinhas locais pode se transmutar numa fonte de incerteza, devido ao pluralismo de sabores imiscuído a determinados saberes periciais da típica culinária regional.

Além disso, os fast-foods são percebidos como uma extensão do espaço público, semelhante aos grandes monumentos, mas com uma vantagem adicional: a plena garantia de anonimato. Diferentemente dos tradicionais cafés, inexiste a preocupação de compra para uso dos banheiros e de fugir do constrangimento de enfrentar o garçom. Por isso, ocasionalmente adentram pela porta do McDonald's não usuários do restaurante. Recordo-me de uma viagem à Holanda, em Amsterdã. Assim como outros turistas, comprei um dos menus do cardápio McDonald's, junto com o lanche, na bandeja, veio uma senha impressa. Por algum momento, não percebi bem qual a serventia daquilo, afinal não havia ecrãs que solicitavam a recolha da bandeja aquando os menus estivessem prontos. Em poucos instantes, formou-se uma fila de usuários e não usuários na ombreira dos toaletes, onde um funcionário fiscalizava e recolhia as senhas. De tal modo que quem não consumisse nada no restaurante deveria comprar uma senha para utilização dos banheiros pelo valor de 1 euro e 50 cêntimos.

Nesse sentido, num duplo processo de ressignificação do espaço, as pessoas, fazendo uso dos recursos materiais disponíveis (ambiência, lugares, mesas vagas, seleção de itens para alimentar-se, sopas, gelados, cafés, cervejas), reapropriam-se do ambiente; por outro lado, o McDonald's é consciente de seus públicos consumidores, logo insere alguns produtos próprios da cultura portuguesa, criando, assim, condições para o primeiro processo. Dessa maneira, encontramos diversos exemplos que confirmam o prospecto sincrético, glocal, repleto de cruzamentos culturais. Por exemplo: é habitual os espanhóis consumirem uma chávena de café com hielo. Para tanto, procedem de uma maneira quase técnica, misturam a porção de açúcar no café, dissolvem bem, e depois, com um único movimento astuto e preciso, lançam a chávena açucarada num segundo recipiente com gelo. Amiúde, escutaram-se sotaques castelhanos solicitando um copo com cubos degelonobalcão doMcCafé.

Outro grupo social que se apropria do espaço de modo nada comum, segundo o comportamento esperado nas redes de fastfood, são os idosos. A idiossincrasia que eles 
fazem do ambiente é digna de um comentário mais detalhado. Em primeiro lugar, esses atores parecem selecionar os itens da ementa consoante aos preceitos tradicionais de encadeamento dos pratos - entrada, prato principal, sobremesa e/ ou café. A sopa, sanduíche, bebida, sorvete e/ ou café se confluem numa combinação, tendo por vistas aquelas heranças culturais de uma alimentação quase ritualizada. A ocasião em que um senhor senta-se próximo a mim e põese a comer o seu menu demonstra bem esse comportamento, vejamos: mescla matrizes culturais portuguesas e europeias, talvez de origem francesa, pelo hábito do consumo da sopa e mais ainda por estender um guardanapo de papel ao colo, além da conduta contida à mesa, movimentos diligentes no mero consumo de um sanduíche.

A sofrósina exibida pelo senhor remete claramente às práticas civilizadas. A sociologia processual de Elias (2000), ao examinar processos em longo prazo, observou que havia uma inclinação à crescente diferenciação e integração social, que se traduz em mecanismos de controlo dos afetos e regulação dos impulsos. Essa sublimação da energia pulsional, nos termos de Freud, conduziu a emergência de modos civilizados que se expandiram em toda Europa e sua origem é mais na França do que na Inglaterra ou Alemanha. Houve um movimento numa direção da popularização das regras de boa conduta à mesa, mesmo que o propósito inicial da classe aristocrática francesa, nessa modelação estética dos costumes, fosse se diferenciar da burguesia.

Em segundo lugar, não se pode negar a natureza sui-generis do McDonald's Imperial, se comparado com o restante das franquias em Portugal, apesar dos esforços de remodelação física, ainda paira na sua existência as noites portuenses no século passado. Sobretudo, no caso dos idosos, essa representação reminiscente ainda transparece vívida. Basta tão-somente fazer referência a uma pequena conversa, parcialmente transcrita, entre duas senhoras para deslindar os meandros dessa analepse:

Faz lembrar "A Brasileira" ", não faz? - recorda a primeira.

É muito espaçoso - responde a segunda.

Estes cafés não são muito comuns, esses sofás, não é? Pois não? - comenta a primeira senhora.

Assim, são previsíveis os usos e apropriações que tais agentes fazem do restaurante. $\mathrm{O}$ aporte reminiscente reconfigura o próprio McCafé. Indivíduos compram um pastel de nata acompanhado de um bule de chá e passam algum tempo conversando, em diálogos prolongados. Constata-se isso pelos gestos, denotando a exposição de assuntos, explicação de pormenores etc. Por vezes, o que acontece dentro e fora do Imperial tornase a temática a partir da qual se desenrola a conversa. Rial (1997) sublinha que, em dada altura, algumas unidades do McDonald's, em Portugal, chegaram ao extremo de substituir o mobiliário por outro ergonomicamente desconfortável: cadeiras altas e inclinadas, com intuito de diminuir o período de permanência dos clientes. Usuários que consomem pouco e prolongam o tempo de estada diminuem, consideravelmente, a "média da bandeja" (RIAL, 1997).

Finalmente, a conjugação de cenários, personagens sociais e comportamentos, que daí

8. O café "A Brasileira" foi inaugurado em 1903, no Porto, porém era muito distinto da atual loja. Anteriormente, era apenas um lugar onde se servia e bebia café, entretanto devido a uma próspera campanha publicitária em linhas férreas e estradas, o sítio de vendas foi separado do café, reabrindo em 1938. "A Brasileira" era popularmente conhecida como café dos artistas em decorrência de sua proximidade com o Teatro Sá da Bandeira, no Porto (COSTA, 2004). 
emergem, cria um panorama de hibridização da realidade, repleto de entrecruzamentos. Por essas e outras que a "Imperial McDonaldização" não é uma pintura de um ou dois tons, mas, sim, um mosaico de pertenças e ressignificações. Pensemos no caso do senhor de suposta origem francesa. O seu comedimento nos modos à mesa remotam à cultura erudita, cultivada, porém ao efetivá-los num contexto de cultura de massas, como é o McDonald's, consumindo um cardápio mais ou menos padronizado da rede de fast food, mas a uma maneira que evoca o slow food, o senhor, seja conscientemente ou não, glocaliza aquela realidade supostamente homogênea e americanizada.

\section{Agradecimentos}

Sou grato ao Prof. Dr. João Teixeira Lopes, docente da Universidade do Porto, pela orientação no trabalho de campo e indicação bibliográfica, a Ivo Emanuel Sampaio Dias, pesquisador da mesma instituição, por ter traduzido simbolicamente umas tantas situações e cenas na observação etnográfica. Agradeço também à Profa Dra Mônica Chaves Abdala e à Prof $\underline{\text { a }}$ Dra Eliane Schmaltz Ferreira, docentes da Universidade Federal de Uberlândia, pela revisão e sugestões críticas às primeiras versões deste artigo.

\section{Referências}

BOURDIEU, P. O campo científico. In: ORTIZ, R (Org.). Pierre Bourdieu: sociologia. São Paulo: Ática, 1994, p. 122-155.

Sobre a televisão. Rio de Janeiro: J. Zahar, 1997.

CLÁUDIO, M. A cidade no bolso. Porto: Campo das Letras, 2000.

COSTA, M. T. Os cafés do Porto. @pha Boletim, Lisboa, v. 2, 2004, p. 1-14. Disponível em: <http://www.apha.pt/boletim/boletim2/pdf/CafesDoPorto.pdf>. Acesso em: 14 jun. 2013.

ELIAS, N. O processo civilizacional. Lisboa: Publicações Dom Quixote, 2000.

GEERTZ, C. Uma descrição densa: por uma teoria interpretativa da cultura. In: A interpretação das culturas. Rio de Janeiro: J. Zahar, 1978, p. 13-41.

GIDDENS, A. Modernidade e identidade pessoal. 2. ed. Oeiras: Celta, 1997.

GOFFMAN, E. A apresentação do eu na vida de todos os dias. Lisboa: Relógio D'Água, 1993.

LOPES, J. T. Tristes escolas: um estudo sobre práticas culturais estudantis no espaço escolar. Porto: Afrontamento, 1997.

A cidade e a cultura. Porto: Afrontamento, 2000.

. Da democratização à democracia cultural: uma reflexão sobre políticas culturais e espaço público. Porto: Profedições, 2008.

MENDES, N. F. F. Cafés históricos do Porto: na demanda de um património ignoto. 2012. $290 f$. Dissertação (Mestrado), Faculdade de Letras da Universidade do Porto, Porto, 2012. 
NAZÁRIO, L. A grande recusa de Herbert Marcuse. Revista Cultura e Vozes, São Paulo, n. 3, p. 76-93, 1998.

PONTES, M. de L. B. Doutoramento honoris causa. Porto: FLUP, 1999.

RIAL, C. S. M. Os fast-foods, uma homogeneidade contestável na globalização cultural. Horizontes Antropológicos, Porto Alegre, v. 5, p. 140-180, 1997.

Submetido em 17 de fevereiro de 2014.

Aprovado em 8 de abril de 2014. 